\title{
Geography Teachers Stories of Sustainability: an introduction to narrative research
}

\section{Abstract}

Geography teacher recruitment and retention is an important issue for the future of geography education. This special issue of IRGEE tackles this issue head on by focussing on geography teachers' narratives about their experiences of teaching geography, and asking why some geography teachers stay in the profession when others leave. This paper serves as an introduction to the special issue, outlining why adopting a narrative approach enables us to gain a deeper understanding of the experience of teaching geography, and why it is important to understand the experience of those teachers that stay in the profession. The theme that emerges from this collection of papers is the significance of the interplay between context and identity when seeking to understand geography teachers' work, and in particular why subject identity matters. These themes are echoed in the other papers of this Special Issue: indicating that now there is sufficient evidence for geography education to take the issue of teacher subject identity seriously, and for further research to consider the implications for initial and continuing teacher education. 


\section{Geography Teachers Stories of Sustainability}

The International Geographical Union's Charter on Geographical Education marks a commitment to the significance and importance of geography education as an entitlement for all young people, and the Rome Declaration on Geography Education highlights the importance of qualified specialist geography teachers. Despite both these of proclamations, geography teacher recruitment and retention remain critical issues around the world. Much of the research on teacher retention has neglected the role of subject identity, and has focussed on the negative impact of neo-liberal education policies on teachers' work. This special edition of IRGEE focuses on geography teachers who are committed to teaching quality geography, and explores what contributes to their sustained commitment, and the role played by their subject expertise.

Changes to curriculum can have an impact on geography education, and always requires quality specialist interpretation. This situation is particularly acute when teachers with no previous background or experience in geography are required to teach the subject. Issues around specialist teaching in geography education are not new and have been widely reported in previous editions of IRGEE (for example, see Barrett-Hacking, 1996; Blankman, van der Schee, Volman, \& Boogaard, 2014; Brooks, 2006; Çokadar, 2013; Corney, 1998; Lee, 2003; Martin, 2005, 2008; Morley, 2012; Özden, 2008; Preston, 2014; Tan, Sharan, \& Lee, 2005; Taylor, Nathan, \& Coll, 2003; Walshe, 2007; Lane, 2014). This special edition attempts to change the conversation by focussing on two specific areas: the research methodologies used to understand geography teachers' identities and on what sustains geography teachers through their career.

\section{Methodological approach: the value of narrative}

The common methodological approach in the papers presented in this special edition is to focus on teachers' own stories about how they understand their work. The use of narrative or narrative- 
inspired research methods is quite different to research that focuses on the implications of changing educational policy or the neoliberal turn. But that is not to say that it does not take such positions seriously. The methodological focus on narrative can be used to shed light on how the experience of teaching is both informed and influenced by the different contexts teachers find themselves in. In other words, it looks at the changing contexts that teachers work in, through their eyes and their experiences.

Narrative enquiry is particularly useful to highlight the complexity of understanding education by focusing on experience. (Parker et al 2011: 5). The value of this approach is that it gives 'voice' to the individual teacher in recounting not just their experiences, but how they make sense of that experience. Therefore, when we look at teachers' narratives or stories, it is important to recognise that the narrative is not necessarily a recollection of actual events, but can represent the individual's meaning-making as he or she generates a narrative to explain and justify his or her actions. This is particularly true of a research situation, where a participant is generating a narrative for the purpose of explaining something to the interviewer. Under these circumstances narratives are constructed to show justification not causality (Goodson et al, 2010). MacLure takes this a step further and calls narrative use within identity research as a form of argument which is: "inescapably moral: identity claims are inevitably bound up with justifications of conduct and belief" (1993: 320). Understanding narrative as argument emphasises the difference between narratives and factual recall: narratives are social constructions that people use to make sense of themselves. However, to understand these narratives, it is important to take them seriously in their own terms and "not just as the expression of something underlying or overarching". (Goodson et al 2010: 127, see also Biesta 2010). This methodological approach is in line with a focus on finding out why individual geography teachers behave in the way they do. The act of teaching geography can be driven by a range of values, brought together by the teacher and made meaningful. 


\section{Sustainability and the teaching of geography}

The second difference in the approach to this special issue is to focus on the idea of sustainability. Traditionally within geography education sustainability is understood as a geographical concept sometimes related to development and as a focus within the geography curriculum. However, in this instance, the term is being used in relation to explore the retention of geography teachers, with a view to understanding what makes some geography teachers stay in the profession when others leave. As Day points out, many studies focus on negative stories: why teachers leave, and the why the profession appears to be so unattractive to prospective teachers (Day, 2012). However, such a perspective can skew our understanding of what it means to be a teacher today. Whilst recruitment and retention are no doubt problems for teaching generally, but in particular for geography education, by understanding why some teachers stay can help us to reconsider our approaches to initial geography teacher education, and how we can prepare pre-service teachers for the reality of teaching geography.

To this end, the call for papers for this special edition asked for papers that focus on:

- theoretical lenses that interrogate geography teachers' practice, particularly that acknowledges the challenges of teaching "today";

- research that identifies the significance of teachers' subject knowledge and identity on their practice;

- narrative/interview based methodologies to elicit teacher's accounts or "stories" of their practice, and their subject expertise.

The papers that follow meet all three of these objectives, each taking a different stance and viewpoint on the experience of teaching geography. Together, the papers highlight the need and importance of research that focus on geography teachers' practice. Moreover, the combination of the papers underlines the significance of teachers having a strong geographical "story". The 
evidence presented suggests that this is an important component which can help to sustain teachers throughout the day-to-day challenges of their work, and longer term through their careers. The geographical spread of papers, combined with other recent articles in this journal, make a clear case that such concerns are international and that there are sufficient similarities across different contexts for a community-wide response.

\section{Professional knowledge landscapes}

The papers in this special issue speak for themselves. However the focus of bringing them together is to recognise that there are commonalities in the experience of teaching geography that exist across national boundaries. To understand this phenomena it is useful to see teachers as working in a professional knowledge landscape. This idea was first introduced by Clandinin and Connelly (1995) who describe these landscapes as being made up of 'sacred stories' which come from official discourses, and which may be in conflict with teachers' own stories of their professional practice. Clandinin and Connelly argue that this creates dilemmas which are knowledge dilemmas as they represent a conflict between official knowledge as represented by policies or directives from their school or official discourses, and the personal knowledge of the teacher. These landscapes can play a profound role in affecting how teachers work and can, in effect, 'make teachers up' in that they can influence not just what teachers do but also who they are (see Brooks 2016).

One of the ways that teachers can respond to these 'sacred stories' in the professional knowledge landscape is to draw upon dimensions of their professional identity which reflect their values about geography, education and teaching. These values can be traced back to a teacher's subject identity: their geographical expertise. In other words, teacher subject identity can be an important driver in how teachers respond to reforms in education.

\section{The importance of teacher identity}


Individual stories about teachers' experiences are important. Large scale surveys like the VITAE project reveal general patterns and trends in teachers' working lives (Day \& Gu, 2007; Day et al., 2007; Sammons et al., 2007)). However to make full use of their findings, we need to understand more about how teachers make sense of their working lives. The VITAE report makes two valuable and important assertions: teachers' commitment can have a positive impact on students' attainment, and that effective teachers require resilience in order to sustain that commitment. However, the research leaves these questions:

- Why are some teachers more committed than others?

- What influences teachers' resilience?

- And what can we do to promote these qualities in future teachers?

The findings, narratives and stories discussed in this special issue throw some light on these questions, particularly for geography teachers. Teacher identity is not static but can change and can be context sensitive. To understand teachers we need to understand the contexts they work in.

Clandinin and Connelly (1995) identify that professional knowledge landscapes are both moral and knowledge-based landscapes. But research in this area has yet to explore the school subject and academic disciplinary contribution to this professional knowledge landscape. Indeed, the recent research on neo-liberal education policies and their impact on schools (Maguire et al 2011; Kaniuka 2012; Hatch 2013) present a challenge to subject-based expertise. These policies can, on one hand, focus on the importance of (subject) knowledge as the basis for teachers' authority, but on the other, represent the teaching profession as one predicated on technical skill and lacking any specific knowledge based component. Teachers can be left wondering what role their subject knowledge can play in their professional practice.

Teachers' responses to pressures around them can be seen as being influenced their values and personal perspectives. In turn, these are often inspired by teacher's own stories of their subject and why it is important, acting like a professional compass on their practice. In the papers presented 
here, there is evidence of such a professional compass in action, and being used by teachers to navigate the school contexts they are working in. The values implicit in a teacher's story about their subject (and why they think it is important) are key in how they relate and respond to where they work and how they choose to teach geography. Previous research has suggested that teachers can choose the extent to which they resist and comply with initiatives (Bowe \& Ball with Gold, 1992), but this is becoming more difficult. Departmental cultures and other networks are also significant in how teachers respond (see Picton 2012 and Roberts 1995 for geography specific examples, as well as Mitchell and Puttick in this volume) but, the extent to which teachers resist and comply is a personal decision, guided by their values.

The attitudes towards teaching expressed by teachers are deeply rooted in their sense of what it means to be a teacher of geography. Their values and beliefs are grounded in their geographical identity, which can be a strong driver for their sustained motivation and for their practice. This analysis goes beyond structural or sociological approaches that defines teacher identity and professionalism in terms of structure and agency. Teachers' understanding of teaching and learning can be connected to their engagement with the subject: what it means to them.

\section{Stories of sustainability}

Each of the papers in this special issue presents a contribution of its own. Together they make an important statement about why researching the experience of geography teachers matters.

Firstly, the collection of papers reveals an understanding that teaching is both identity work and collective work: individual work that is undertaken in a social context (which Alexandre describes as a form of social representation). The implication of this perspective on geography teachers' identity is significant. Part of the neoliberal education context is that it treats individuals as subjects who believe they are acting in their self-interest but who can be viewed as acting in line with the neoliberal agenda. Revealing the effect this has on individuals, and how it is manifest in their 
practice and understanding of practice, is an important dimension in understanding the complexity of teachers' work, and in particular the significance of having a subject-based identity.

Each of the five papers that follows explores this relationship between identity and the social context in different ways, revealing different dimensions to this relationship. Silvas et al's paper focuses on what teachers expertise looks like in a particular context. Researching with teachers in rural parts of Chile, the research reveals that these teachers have different types of expertise, which can be categorised as being: sensory in that it is based on experience; political as a pretext to local action; and, subversive in that it may not connect with national requirements. The paper argues that this is a kind of practical wisdom which is related to their contexts as teachers in rural communities. This practical wisdom is not gained through teacher certification programmes, but is part of the experience that they gain through their professional identity and the role that they recognise for themselves in their community. By understanding the expertise of these teachers as being influenced by their geographical context, this paper shows how important contexts can be in shaping individual teacher's identity: echoing the observation that the interplay between context and identity is paramount.

Taking this theme of context to a different scale, Mitchell's paper studies the workings of geography departments in London. His analysis is focussed on how those departments make the geography curriculum, and reveals processes that he describes as a form of hyper-socialisation. This research also privileges the contexts that teachers work in but sees this context as a social landscape, which is particularly influential when it operates as a supportive network acting as a locus of curriculum generation.

Sticking with the scale of the geography department, Puttick's research focuses on how stories, and in particular collective and shared stories, can sustain and motivate teachers. This research emphasises how important these stories are, particularly when they are linked to teachers' personal lives, a perspective Puttick describes as a teleological view which is deeply rooted in the history of 
their own life. Puttick's research also shows how these narratives can be seen as being both individual and collective. They are a retelling of stories, shared narratives, which reveal the discursive positioning of individual teachers within a shared social context.

The next paper serves as an important reminder that such social contexts are not completely free. Seow's paper reminds us that we need to see preservice teachers' subject conceptions and practice explicitly as responses to discursive contexts. This research highlights the changing nature of discourse and the impact of power relationships on geography teachers' knowledge and practice. It reveals how such discursive environments can affect preservice teacher's subject conceptions, their developing identity of becoming a geography teachers and how they react to such contexts: both in terms of how they comply and how they resist. Seow's work acts as a timely reminder that context and identity are mutually constructive: a negotiation of discourse.

Finally, Alexandre's paper critiques the validity of focussing on teacher beliefs, and explores social representations as an alternative. This exploration of social representation stems from two interconnected processes:

- The development of teachers social representation systems as the foundation of their subject and professional knowledge

- The development of their professional identity.

The professional representation of identity is activated when teachers are confronted with a specific inter-relational context, and they have to identify with a particular group. Alexandre's paper reminds us that geography teachers' identities are often "on show".

\section{Looking to the future}

Taking these papers together, reveals some of the effects of the interplay between context and identity specifically for geography teachers. There are gaps of course. All of the papers focus on secondary school age geography teachers. The context of the primary school geography teacher is 
very different, not to mention the complex identity work of a subject specialist within the primary school. The papers also define context, and to some extent, identity differently. The methodological approach of using narrative research has been criticised as being overly reflective and self-indulgent, but as these papers can be illuminative about the experience of being a professional educator.

A practical and technical approach to initial and continuing teacher education can only go so far in developing resilient and committed geography teachers. If we want a geography teaching community that can respond to the changing economic, social and educational world in a principled, ethical and informed way, then we need to consider the people who are teaching geography; and what they are doing it for. We need to understand the situations they face, and their experience of professional practice, and the impact this can have on them as individuals. This is ongoing work. Once we understand these relationships better, then we can use this information to inform how we interact with pre-service and in-service teachers. In other words, identity research with geography teachers should be ongoing to build a body of evidence of what it means to teach geography. As our understanding of geography teacher identity grows, so it can be used to inform teacher education programmes; to build a body of expert specialist knowledge, and a robust teacher identity that sustains teachers through changing times. I have described this as understanding teacher subject identity as a professional compass (see Brooks 2016). The future challenge is how we can adapt geography teacher education programmes so that teachers develop such a professional compass to help them navigate changing and challenging professional knowledge landscapes.

\section{References}

Ball, S. J., Maguire, M., \& Braun, A. (2012). How Schools Do Policy: Policy Enactments in Secondary Schools. London: Routledge.

Barrett-Hacking, E. (1996). Novice Teachers and their Geographical Persuasions. International Research in Geographical and Environmental Education, 5(1), 77-86. 
Beauchamp, C., \& Thomas, L. (2009). Understanding teacher identity: an overview of issues in the literature and implications for teacher education. Cambridge Journal of Education, 39(2), 175-189. doi:10.1080/03057640902902252

Biesta, G. (2010). Good education in an age of measurement : ethics, politics, democracy. Boulder, Colo.: Paradigm.

Blankman, M., van der Schee, J., Volman, M., \& Boogaard, M. (2014). Primary teacher educators' perception of desired and achieved pedagogical content knowledge in geography education in primary teacher training. International Research in Geographical and Environmental Education, 24(1), 80-94. doi:10.1080/10382046.2014.967110

Bowe, R., Ball, S. J., \& with Gold, A. (1992). Reforming Education and Changing Schools: case studies in policy sociology. London: Routledge.

Brooks, C. (2006). Geographical Knowledge and Teaching Geography. International Research in Geographical and Environmental Education, 15(4), 353-369. doi:10.2167/irg200.0

Brooks, C. (2016). Teacher Subject Identity in Professional Practice: Teaching with a professional compass. London: Routledge.

Clandinin, D. J., \& Connelly, F. M. (1995). Teachers' Professional Knowledge Landscapes. New York: Teachers College Press.

Çokadar, H. (2013). Elementary science trainee teachers' perceptions and conceptual models of the ozone layer. International Research in Geographical and Environmental Education, 22(3), 259-274. doi:10.1080/10382046.2013.817656

Corney, G. (1998). Learning to Teach Environmental Issues. International Research in Geographical and Environmental Education, 7(2), 90-105. doi:10.1080/10382049808667562

Day, C. (2012). New lives of teachers. Teacher Education Quarterly, 39(1), 7-26.

Day, C., \& Gu, Q. (2007). Variations in the conditions for teachers' professional learning and development: sustaining commitment and effectiveness over a career. Oxford Review of Education, 33(4), 423-443. doi:10.1080/03054980701450746 
Day, C., Sammons, P., Stobart, G., Kington, A., \& Gu, Q. (2007). Teachers matter : connecting work, lives and effectiveness. Maidenhead: Open UP/McGraw-Hill.

Fang, Z. (1996). A review of research on teacher beliefs and practices. Educational Research, 38(1), 47-65. doi:10.1080/0013188960380104

Goodson, I. F., Biesta, G., Tedder, M., \& Adair, N. (2010). Narrative learning. Abingdon: Routledge.

Hargreaves, A. (2001). Emotional Geographies of Teaching. Teachers College Record, 103(6), 10561080.

Hatch, T. (2013). Beneath the surface of accountability: Answerability, responsibility and capacitybuilding in recent education reforms in Norway. Journal of Educational Change, 14(2), 113138. doi:10.1007/s10833-012-9206-1

Kaniuka, T. S. (2012). Toward an understanding of how teachers change during school reform: Considerations for educational leadership and school improvement. Journal of Educational Change, 13(3), 327-346. doi:10.1007/s10833-012-9184-3

Lane, R. (2014). Experienced geography teachers' PCK of students' ideas and beliefs about learning and teaching. International Research in Geographical and Environmental Education, 24(1), 43-57. doi:10.1080/10382046.2014.967113

Lee, C. K.-e. (2003). Research on Learning to Teach : Lessons for the Professional Preparation of Preservice Geography Teachers at NIE. International Research in Geographical and Environmental Education, 12(3), 275-283.

MacLure, M. (1993). Arguing for Your Self: Identity as an Organising Principle in Teachers' Jobs and Lives. British Educational Research Journal, 19(4), 311-322.

Maguire, M., Perryman, J., Ball, S., \& Braun, A. (2011). The ordinary school - what is it? British Journal of Sociology of Education, 32(1), 1-16. doi:10.1080/01425692.2011.527718

Martin, F. (2005). Ethnogeography: A Future for Primary Geography and Primary Geography Research? International Research in Geographical and Environmental Education, 14(4), 364371. doi:10.1080/10382040508668372 
Martin, F. (2008). Knowledge Bases for Effective Teaching: Beginning Teachers' Development As Teachers of Primary Geography. International Research in Geographical and Environmental Education, 17(1), 13-39. doi:10.2167/irgee226.0

Morley, E. (2012). English primary trainee teachers' perceptions of geography. International Research in Geographical and Environmental Education, 21(2), 123-137. doi:10.1080/10382046.2012.672678

Özden, M. (2008). Environmental Awareness and Attitudes of Student Teachers: An Empirical Research. International Research in Geographical and Environmental Education, 17(1), 4055. doi:10.2167/irgee227.0

Parker, D. C., Pushor, D., \& Kitchen, J. (2011). Narrative inquiry, curriculum making, and teacher education. In J. Kitchen, D. C. Parker, \& D. Pushor (Eds.), Narrative inquiries into curriculum making in teacher education (pp. 3-18). Bingley: Emerald.

Picton, O. (2012). Teachers ' understandings of geographical concepts. Teaching Geography(3), 3-4.

Preston, L. (2014). Australian primary in-service teachers' conceptions of geography. International Research in Geographical and Environmental Education, 24(2), 167-180. doi:10.1080/10382046.2014.993173

Roberts, M. (1995). Interpretations of the Geography National Curriculum: a common curriculum for all? Journal of Curriculum Studies, 27(2), 187-205. doi:10.1080/0022027950270204

Sachs, J. (2003). The Activist Teaching Profession. Maidenhead: Open University Press.

Sammons, P., Day, C., Kington, A., Gu, Q., Stobart, G., \& Smees, R. (2007). Exploring variations in teachers' work, lives and their effects on pupils: key findings and implications from a longitudinal mixed-method study. British Educational Research Journal, 33(5), 681-701. doi:10.1080/01411920701582264

Tan, I. G.-C., Sharan, S., \& Lee, C. K.-E. (2005). Students' Perceptions of Learning Geography through Group Investigation in Singapore. International Research in Geographical and Environmental Education, 14(4), 261-276. doi:10.1080/10382040508668359 
Taylor, N., Nathan, S., \& Coll, R. K. (2003). Education for Sustainability in Regional New South Wales, Australia: An Exploratory Study of Some Teachers' Perceptions. International Research in Geographical and Environmental Education, 12(4), 291-311.

doi:10.1080/10382040308667543

Walshe, N. (2007). Understanding Teachers' Conceptualisations of Geography. International Research in Geographical and Environmental Education, 16(2), 97-119.

doi:10.2167/irgee212.0 